Sebastián Edwards, Conversación interrumpida. Memorias (Santiago: Ediciones Universidad Diego Portales, 2016).

RESEÑA

\title{
CHILE A TRAVÉS DEL ESPEJO
}

\section{Neil Davidson}

Escritor

E 1 actor Leonard Nimoy, más conocido como el Señor Spock de - Viaje a las estrellas, publicó la historia de su vida en dos tomos,
poniéndole al primero el título No soy Spock, y al segundo, Soy Spock. Rara vez se ha respondido tan nítida a la vez que tan equívocamente a la interrogante que enfrenta todo autobiógrafo a la hora de bautizar su obra. ¿Definirse o no? ¿Aferrarse a la ilusión juvenil de que cualquier vida es posible o declarar que la suya ya se definió y no será otra?

El memorialista, sin embargo, como sólo promete recuerdos y no definiciones, se sustrae a ese problema. Es a ese formato distendido que pertenece Conversación interrumpida,${ }^{1}$ reencuentro del economista Sebastián Edwards con su propio pasado luego de la muerte de su padre y culminación, se podría decir, de un viaje de acercamiento literario a su país de origen. Radicado desde 1977 en Estados Unidos, donde se ha desempeñado, entre otras cosas, como economista jefe para América Latina y el Caribe del Banco Mundial y ahora como profesor Henry Ford II de economía internacional en la Anderson Graduate School of Management de la UCLA, SE ha publicado desde la década de 1980 una serie de libros sobre la economía política del desarrollo, enfocados especial-

Neil Davidson. Escritor y columnista. Estudió lingüística y literatura francesa e italiana en la Universidad de Durham. Sus últimos libros son The Chilean Way (2010); El ceño radiante. Vida y poesía de Gerard Manley Hopkins (2015) y Usted está muymal (2017). Email: davidsonneilat@gmail.com

${ }^{1}$ Santiago: Ediciones Universidad Diego Portales, 2016. En adelante nos referiremos al autor como SE y las citas al libro se identificarán tan sólo con el número de página. 
mente en Latinoamérica, pero escritos en inglés. En la última década, ha sumado a su oficio de economista el de novelista popular latinoamericano, componiendo en el dialecto del gremio - un español hemisférico con toques anglosajones - unas tramas ambientadas principalmente también en Latinoamérica, continente que, al igual que Europa, va adquiriendo una unidad cada vez mayor a medida que uno se aleja de él. Y ahora, con Conversación interrumpida, ha aterrizado en Chile.

La hélice aún gira, sin embargo, y el libro parte como una obra de ficción narrada en primera persona: "Volví a mirar la pequeña caja de madera que contenía los restos de mi padre. Sentí un escalofrío y respiré hondo mientras ajustaba nuevamente la bufanda a mi cuello" (13). Este efecto de distanciamiento y de recogimiento vale para la situación del autor al disponerse a esparcir las cenizas de su padre en el océano, pero también para la empresa literaria a la cual está abocado: la conversación a la que alude el título del libro era la que mantenía justamente con su padre, Hernán Edwards Cruchaga, y que se interrumpió cuando SE abandonó Chile a los 23 años ante la amenaza de una persecución oficial. Convertido en estudiante de economía en la Universidad de Chicago, echaría de menos ese diálogo a tal punto que: "Un día, caminando desde la universidad hasta nuestro departamento en Hyde Park Boulevard, me di cuenta de que le hablaba permanentemente. Mantenía en mi cabeza un diálogo persistente, le comentaba lo que me pasaba, lo que aprendía en las diferentes clases, y lo que veía en la ciudad; le hacía preguntas y le pedía su opinión; le hablaba de mi pequeña hija Magdalena, de sus avances y sus experiencias" (15). La separación era tanto más penosa porque le había costado a SE reconciliarse con su padre luego de que éste abandonara su matrimonio y la casa familiar. A pesar de las cartas y luego las visitas - cuyo carácter a menudo forzado todo expatriado conoce- - la relación nunca se reanudaría en forma satisfactoria. "Alguna vez tendríamos el tiempo para hablar, para decirnos todo lo callado durante años, para contestar la pregunta de la oruga en Alicia a través del espejo: ‘¿Quién eres tú?’. Pero la llegada de las nubes oscuras del Alzheimer descarriló el plan y dejó la consulta de la oruga sin respuesta, o, quizás, con una respuesta a medias" (16). El libro sería la continuación, entonces, de ese diálogo y forma "parte del reencuentro con mis orígenes y mi pasado. Después de tantos años de ausencias y resquemores, de pronto se me hizo necesario" (17). 
A primera vista, ese origen del libro no se nota mucho. Todo escrito que responde a una necesidad interior parte con un monólogo o un diálogo unilateral de algún tipo. Puede ir dirigido a un público invisible, a una persona en particular o al éter, pero, una vez hecho el trabajo del interlocutor imaginario, es difícil que el lector sepa quién era, a menos que el autor se lo divulgue. Aparte de su evidente interés biográfico en sí, entonces, la información de que se trata del padre en este caso le sirve al lector principalmente para formarse una expectativa del tipo de libro que le espera: no la narración a secas de acontecimientos históricos o la evolución intelectual de un economista, sino un documento mucho más personal.

Esa expectativa queda parcialmente frustrada. Aunque se trata en efecto de un libro muy personal, el lector buscará en vano retratos de Magdalena, la hija mencionada en su introducción, o de María Ignacia, la hermana a la cual está dedicado, o de otros miembros de la familia, como un hermano que se nombra para luego desaparecer como fantasma. En una oportunidad, SE vuelve de la universidad a la casa y le pide a su madre ayudarlo a leer El capital en francés: "Me miró durante unos segundos, luego preguntó si estaba loco. Sin más, salió de la sala y me dejó solo" (97). ¿Simplemente la reacción de una madre cuyo hijo se ha transformado en fanático socialista, o debería entenderse algo más? No hay cómo saberlo, porque hasta ahora apenas se ha mencionado, y nunca se formará una imagen clara de ella. Hay un padrastro por ahí, pero la primera noticia que hay de él es cuando hace un comentario sobre el Golpe de Estado que todos están esperando "en un tono serio muy poco característico en él" (126). Se deduce que su tono habitual era poco serio. Mucho después, retará al autor por usar su tocadiscos.

Pensé por un tiempo que el libro iba dirigido a lectores que ya conocían a la familia y no necesitaban detalles, pero al llegar al capítulo 35, donde SE empieza a hablar más directamente del padre, creí entender. Para describir a éste, tiene que dirigirse al lector. Hasta ese punto, sin embargo, parece que se ha dirigido en efecto al padre mismo, y no tiene para qué describirle lo que ya conoce, como el carácter de sus propios hijos, sus nietos o su ex esposa.

En todo caso, el retrato del siempre endeudado Hernán Edwards, mujeriego compulsivo que deja su matrimonio pero nunca ceja en sus intentos por fortalecer la relación con su hijo, es cautivante y sin duda 
explica gran parte del interés que ha suscitado Conversación interrumpida. Otros ingredientes parecieran de interés menos general. SE dedica mucho espacio, por ejemplo, a las influencias intelectuales en su formación como persona y, sobre todo, como economista, y pensé en algo que dijo alguna vez el director de orquesta Thomas Beecham sobre otra disciplina matemática: "A la mayor parte de la gente no le gusta la música, sólo le gusta cómo suena". Asimismo, a la mayor parte de la gente le gusta la baja inflación, el pleno empleo y la abundancia, pero prescinde sin complejos de toda información sobre cómo se consiguieron, y habla bien de la pluma de SE el que ese aspecto del libro sea tan ameno, sobre toda la sección larga "Chicago sin Milton Friedman", dedicada al paso de SE por la Universidad de Chicago, donde describe sesiones agotadoras de estudio en la biblioteca, además de los profesores que le tocaron y las personas famosas con las cuales se iba topando en sus aulas y sus pasillos.

Pero el núcleo de Conversación interrumpida es, sin duda, su descripción del período más crítico de la historia moderna de Chile —el del gobierno de la Unidad Popular y el comienzo de la dictadura- y del papel sorprendentemente protagónico que tuvo SE en esos eventos. Ya a los dieciséis años, siendo alumno de un colegio particular de corte inglés y conservador, el Grange, y a pesar de una aversión innata a la acción grupal, era no solamente partidario de Salvador Allende, sino que también militante del Contingente Lenin del Partido Socialista. El suyo era un marxismo chileno: un motivo importante de su elección del Partido Socialista para su militancia fue que era "un partido de verdad chileno y popular" (50), que nunca se había afiliado al Comintern. La tierra prometida era, por supuesto, Cuba, adonde se habría dirigido en 1970 para participar en la zafra de los diez millones si no fuera por la rigidez de la burocracia cubana, que le impidió viajar.

Lo que inspiraba su postura política era "la idea vaga y luminosa de construir una sociedad donde... las personas pudieran hacer lo que quisieran" (74). Ahora es fácil ver cuán rápidamente semejante concepción debía estallar contra la realidad, sobre todo si a SE, como él afirma, la retórica marxista, los uniformes y el culto a la personalidad de Castro le parecían más bien pueriles. "Mi affaire con el socialismo de trinchera duró cuatro o cinco años" (73), y los motivos de desencanto fueron los habituales, como la persecución de Heberto Padilla y otras 
represiones que se venían informando desde Cuba mientras Castro desplegaba una retórica gloriosa en su visita a Chile de 1972. A mediados de 1973, ahora como estudiante en la Facultad de Economía Política de la Universidad de Chile, "sin abandonar mi apoyo a Salvador Allende, entendí que tenía que alejarme del partido, de todos los partidos, para emprender un viaje de regreso a la soledad" (82). Luego vino el Golpe y la clausura de la facultad por orden de los militares, "por ser un centro de izquierdistas y revolucionarios, de indeseables y de vagos" (21). SE postuló al Instituto de Economía de la Universidad Católica, donde terminó sus estudios de grado y se convirtió en profesor. Como él evidentemente entiende, por la vehemencia con que afirma, entre otras declaraciones, que "nunca iba a trabajar para Pinochet" (37), su abandono de la militancia justo cuando la UP estaba claramente naufragando, seguido por su ingreso en el reducto mismo de los Chicago Boys, tan estrechamente vinculado al régimen militar, podría prestarse a una interpretación desfavorable; pero su temeridad posterior, que lo llevaría al exilio, es una respuesta suficiente a toda sospecha de oportunismo más allá del que exige una ambición razonable.

Vivió antes del Golpe, entonces, una militancia socialista que, aunque varía poco de país en país y de década en década, nunca pierde su interés. En una reunión, un compañero le lanza un ataque verbal desbordado con el que lo acusa de simpatías socialdemócratas: ha descubierto que SE lee libros burgueses como La montaña mágica y Moby Dick. Sus profesores de la Universidad de Chile encuentran que "el esfuerzo de Stalin en 1929 por erradicar [la tenencia de tierra privada] entre los campesinos rusos y ucranianos era justificado, sin importar el horror y la muerte de millones de personas" (103). Los estudiantes, para poner fin a la explotación, deciden expulsar a la concesionaria del casino y crear un colectivo de obreros para administrarlo, y SE observa cómo, a través de las semanas, va desapareciendo el pan fresco y reduciéndose cada vez más el horario de apertura.

Esa experiencia culmina a principios de 1973, cuando SE es asignado, gracias a sus contactos políticos, a la Dirección General de Comercio (Dirinco) como asistente personal del director de costos y precios, Boris Riedemann. A los 19 años de edad, entonces, se convierte en el conducto para todas las solicitudes de aumento de precios que llegan desde las empresas. Sería mucho decir que tenía el futuro del país en sus manos porque, hiciera lo que hiciera, el modelo seguramente era in- 
salvable, pero sí podía llevar una gran empresa hacia la quiebra simplemente dejando su expediente en el fondo de una pila. Las situaciones de ese tipo son el antídoto a la noción de que la vida tiene sentido. El corazón de la Dirinco era una gran sala donde se desempeñaba un ejército de contadores amargados en medio de rivalidades y sabotajes mutuos que entorpecían aún más un trabajo ya imposible. Es el tipo de lugar que tiende a quedar marginado de la historia porque ningún escritor llega ahí, pero SE, como un Kipling infiltrado entre administradores y soldados en los clubes y comedores de regimiento del Imperio Británico, sí llega y consigna una descripción inolvidable cuyo único defecto es su brevedad. Como los precios de los bienes están siempre rezagados respecto a su costo de producción, en la práctica la Dirinco es una máquina para generar escasez. SE entonces le propone a su jefe un sistema para calcular precios más adecuados, basado en una gran matriz de insumoproducto y el procesamiento con un computador potente de datos permanentemente actualizados. "[Riedemann] me miró como si estuviera loco. Me explicó que para que ese sistema funcionara en la práctica la matriz de insumo-producto debía considerar a lo menos tres mil bienes, lo que significaba que tendría nueve millones de celdas... 'Este es el mundo real, compañero', agregó con una sonrisa sarcástica” (119).

Puesto que un computador moderno despacharía sin dificultad el volumen de cálculos que esa cifra implica, debe ser sólo cuestión de tiempo para que se lleve a la práctica la sugerencia de SE en algún lugar del mundo, con el argumento de que todos los intentos anteriores por implementar un socialismo científico fueron prematuros. Un signo del éxito sería que nada cambiaría mucho, pues los precios, como señala $\mathrm{SE}$, serían parecidos, aunque no idénticos, a los de mercado.

Trabajar en el corazón de una economía planificada evidentemente aportó al desencanto político de SE, aun si la experiencia, como me imagino, debe provocar cierta envidia entre colegas que sólo conocen de primera mano el libre mercado. Pero la desilusión fue gradual: luego de comenzar sus estudios en Chicago, se demoró en abandonar su intención original de estudiar en alguna universidad inglesa de corte más keynesiano, y a finales de 1980, al tener que elegir a un pensador del pasado para un ensayo que le pedía uno de sus profesores, George Stigler, optó por Marx y quedó sin palabras cuando Stigler reaccionó no con interés o siquiera horror, sino con extrañeza ante la elección de 
un economista tan mediocre, comentando que "su teoría del valor es incorrecta y su análisis sobre el dinero es de una fragilidad pasmosa" (184). SE resalta el valor de la experiencia práctica para un economista - “más que los cursos, los teoremas y las ecuaciones", fueron los viajes con su mentor Arnold Harberger "los que más influyeron en mi formación" (170)—, y su pasado socialista aún le sirve de referente. Llama la atención, en todo caso, que en un libro reciente, Toxic Aid: Economic Collapse and Recovery in Tanzania, ${ }^{2}$ SE eligió estudiar el experimento socialista bajo las condiciones más favorables, en el sentido de que su fracaso en ese caso no se puede imputar al sabotaje externo, como con cierta verosimilitud se puede plantear respecto de países como Chile y Cuba, sino que fue apoyado con entusiasmo por la comunidad internacional.

SE está todavía inmerso en la Dirinco cuando viene el Golpe de Estado a instalar otro "mundo real" no menos absurdo que el anterior, pero con el agregado de la violencia y la indecencia sistematizadas. Abolido su empleo, clausurada la Facultad de Economía de la Universidad de Chile, imposibilitada la actividad política que había consumido gran parte de su tiempo, se ve constreñido al ocio. Los primeros días son de "parálisis y miedo" (132), pero aun así se anima a salir en su citroneta por las calles "infestadas" de patrullas, y su madre vuelve a aparecer, primero para confiscar las llaves, luego para decirle que las extravió. SE no ha heredado su instinto de supervivencia: echa a andar el furgón conectando los cables debajo del tablero, y es ella nuevamente la encargada de explicarle cómo podrían interpretar esa conducta las fuerzas del orden. Al miedo le sucede el aburrimiento, y es en ese trance, a los tres meses del Golpe, que un amigo de SE, Felipe Montt, sugiere que postulen a la Universidad Católica, el hogar mismo de los Chicago Boys. Es "una idea audaz, casi descabellada, pero no teníamos nada que perder" (21). Un amigo de la hermana de Montt trabaja en el comité, y su postulación es exitosa.

Si en la Universidad de Chile SE era un "pequeño burgués y revisionista" (77), en palabras de un compañero que dudaba de su compromiso socialista, en la Católica, por su militancia anterior, se transforma en uno de los "traidores de clase, que se levantan en contra de sus

\footnotetext{
${ }^{2}$ Oxford: Oxford University Press, 2014.
} 
propias familias" (24). Pero el cambio no podría ser más afortunado desde el punto de vista de su futura carrera. En vez de leer los escritos de Marx y Engels con vistas a la administración de una economía cerrada, estudia la disciplina moderna en toda su amplitud: "Mi amor instantáneo fue la teoría pura del comercio internacional" (28). Bajo sospecha, neutralizado políticamente, no tiene distracciones que le impidan estudiar, y le va bien. Recibido como el mejor alumno de su promoción, empezará a dar clases en el Instituto de Economía, primero como ayudante de Miguel Kast en la cátedra de teoría monetaria, luego como profesor asistente encargado de esa misma cátedra. Su éxito atrae la atención de las autoridades, y en marzo de 1976 llama Kast al director del instituto, Dominique Hachette, para compartir la consternación del gobierno por el hecho de que alguien como SE esté impartiendo el curso más importante de la carrera. SE es destituido, pero ha recibido una oferta de trabajo de Rolf Lüders, vicepresidente del Grupo BHC, en cuyo departamento de estudios económicos entra a trabajar. Kast lo vuelve a acosar, pero Lüders lo protege, y a principios de 1977 lo favorece aún más dándole permiso para estudiar un doctorado afuera y ofreciéndole un préstamo para cubrir sus gastos. En junio de ese año, SE publica un artículo en la revista Qué Pasa en el que expone la precariedad de la visión económica propugnada por José Piñera, el primer gurú de Pinochet, según la cual Chile alcanzaría a Suecia en lo económico y lo social en una generación, con un crecimiento de 8 por ciento anual. Piñera se enfurece y el nombre de SE va subiendo en la lista de los indeseables. Su vida corre peligro, y en agosto parte con su familia a la Universidad de Chicago. Sigue radicado en Estados Unidos hasta hoy.

Hay mucho más en Conversación interrumpida aparte de esta secuencia central. SE entra como bombero en la Primera Compañía poco después del Golpe. Hace su servicio militar mientras está en el Grange. Es el único alumno hombre del colegio de su abuela, La Girouette. Su madre emprende un viaje de cuatro meses a Europa con un grupo de alumnas, y a su regreso se separa. SE casi sufre un abuso sexual en otro colegio, los Sagrados Corazones, y años después se topa en Honduras con el abusador, que ahora está a cargo de un equipo de fútbol infantil. Describe una batalla entre hippies y cadetes de la Escuela Militar en 1968, y habla de su vida erótica, incluyendo sus visitas a un prostíbulo de la calle Jofré, célebre en su momento. Como estudiante de la Uni- 
versidad de Chicago, conoce a celebridades como Paul Ricoeur y Saul Bellow, y trabaja para el renombrado economista Arnold Harberger, acompañándolo a distintos países en misiones de asesoría. Son a menudo escenas aisladas, dispersión que se justifica por la intención declarada de SE de evocar aspectos de la vida chilena de los años sesenta y setenta que han quedado intactos en su memoria, pero que la historia no ha rescatado. Menos intencional, quizás, es la confusión que produce a veces la estructura narrativa que ha escogido, con cortes y saltos entre distintas etapas de su vida. Ese método aporta cierto dramatismo por el acercamiento de causas y consecuencias o el resalte de contrastes, y es más efectivo en las secciones que tratan sobre los años de la UP y los comienzos de la dictadura, cuya cronología el lector ya conoce. Pero en otros momentos éste tiene que concentrarse para no perder el hilo, y aun en la secuencia central la técnica no siempre es exitosa. En el capítulo 17, por ejemplo, cuando el historiador Claudio Véliz cautiva a los amotinados del tanquetazo de junio de 1973 con una clase de historia improvisada, es desconcertante descubrir que SE ya ha hecho su servicio militar, episodio que recién se describirá hacia el final del libro.

Observé al principio de esta reseña que el memorialista no está obligado a darle coherencia a sus recuerdos. Puede suceder, sin embargo, y ha sido mi caso aquí, que al lector se le vaya componiendo un patrón que no queda explícito en la obra. Tenderá sin duda a proyectarle prejuicios y experiencias propios, incluyendo en mi caso un cambio de país que pareció estar motivado en su momento por consideraciones prácticas y más bien ajenas a mi voluntad, pero que en realidad, según me parece ahora, me sirvió para solucionar o evadir problemas de los cuales no estaba del todo consciente. Como algo parecido parece desprenderse en el caso de SE, voy a permitirme algunas especulaciones, con la reserva de que se aplican al Sebastián Edwards de Conversación interrumpida, pero no necesariamente a la persona del mismo nombre que existe en la vida real, ya que de él sé sólo lo que le ha parecido conveniente divulgar en el libro.

SE era muy joven, con menos de 25 años, cuando desmontó la visión económica de José Piñera en su artículo para Qué Pasa. Ya se ha advertido una veta temeraria en su carácter, evidenciada además en otros episodios del libro, como la ayuda que le presta a un compañero para transportar armas durante el gobierno de la UP. Otra característica 
suya es el afán de rigurosidad intelectual, y ante la reacción violenta de Piñera se muestra sorprendido de que alguien pueda alterarse tanto por el tipo de desacuerdo profesional que es rutinario en su disciplina. Sólo tras dos advertencias enfáticas, emitidas por su tío Gonzalo Figueroa y un ex compañero de colegio que trabaja en los servicios de inteligencia, se convence de que corre peligro y tiene que irse del país.

Pero su sorpresa es, a su vez, un poco desconcertante. SE ya se ha aprovechado del formato del reparo técnico para levantar la misma protesta contra el régimen, aunque en forma mucho menos pública. Se trata del caso de un profesor que tuvo en la Universidad Católica, Patricio Meller: reprendido éste por criticar las políticas económicas del régimen en el aula, SE, a sabiendas de que algún alumno debe haberlo delatado y no se puede hablar abiertamente, decide "hacerle una pregunta técnica sobre el material de clases... Era una duda puramente matemática... Sin embargo, la respuesta, también técnica y árida, repetía en términos abstractos, generales y matemáticos lo que Meller había dicho en clases: varias de las políticas impulsadas por los Chicago Boys eran simplistas y doctrinarias" (28). Si hacer eso en una clase ya bordea el peligro, tanto más peligroso es criticar en una revista nacional a alguien como José Piñera, que se pone "un poco molesto" (83) por una simple interrupción mientras está conversando. Ofender a José Piñera es ofender al régimen, y SE conoce muy bien la naturaleza de éste, como lo expresa con elocuencia en relación a una conversación que tuvo con Kast a principios de 1975. Éste le habló con entusiasmo del catolicismo y del gran trabajo que iba a hacer el régimen para los pobres, y SE comenta: "Al salir de su casa, ya bien entrada la noche, me parecía estar viviendo en dos mundos paralelos: uno, en apariencia amable y simple, donde la religión y las fuerzas del mercado eran los principios que guiaban vidas y comportamientos, y otro repleto de miedo, desapariciones y desesperación" (33).

Pareciera que, aunque fuera en forma inconsciente, SE quería provocar la reacción que lo obligaría a exiliarse. No simplemente irse del país - eso lo iba a hacer de todas maneras, para estudiar un doctorado- - sino hacerlo sin posibilidad de regreso, al menos mientras durara la dictadura. En rigor, tendría que volver, porque su padre sería deudor solidario del préstamo que le otorgaba el Grupo BHC y quedaría en la ruina si SE no llegaba a cumplir su promesa de volver a trabajar para 
el Grupo. Pero siempre hay soluciones para los problemas de ese tipo, y en efecto se encontrará una cuando un profesor de Chicago, Sherwin Rosen, ofrece formar un sindicato para comprar la deuda. Aparte de eso, el exilio es un procedimiento lógico. La carrera académica de alto nivel que quiere SE le está cerrada en Chile, y con el exilio se liberará no solamente de la distracción representada por la posibilidad de volver, sino que también de cualquier culpa que pueda sentir por haber pasado al campo del enemigo al matricularse en la Católica. Y si esos motivos fueran insuficientes, hay ciertas pistas en el libro que indican otro, más de fondo.

Aun antes de abrir Conversación interrumpida, el lector con la más mínima conciencia de la realidad social chilena ya se habrá formado una opinión de su autor simplemente por su apellido. SE lo sabe, y casi lo primero que hace es intentar echar por tierra esa preconcepción. Según la presenta, la suya fue una infancia marcada por la pobreza y los sentimientos de inferioridad. Cuenta cómo en algún momento su padre exige saber por qué no se parece más a los hijos de su novia más reciente:

La pregunta me golpeó. Me encerré en mi dormitorio e hice una lista con los atributos de esos niños: iban a un colegio católico, yo no; tocaban instrumentos musicales, mientras que lo único que a mí me interesaba era el fútbol; eran limpios y estaban siempre bien peinados, mientras yo tenía las uñas sucias y los pantalones rotos en las rodillas; tenían una madre artista, y la mía trabajaba en el colegio de mi abuela; el padre de ellos vivía en Miami y les enviaba las últimas novedades discográficas, mientras que el mío vivía en una casa antigua y derruida en una parcela en La Florida. El balance no podía ser más claro: esos niños eran "ganadores", y por más que yo me esforzara jamás lograría ser como ellos. Mi única defensa era callar y apartarme, partir y desaparecer. (14)

En realidad, la primera impresión del lector es, a grandes rasgos, correcta. SE es un Edwards de alcurnia, chozno de George, bisnieto de Eliodoro Yáñez. La casa "antigua y derruida", comprada por el abuelo en los años 30, resulta ser "enorme", con un "jardín laberíntico" (235) y una cancha de tenis. La abuela es dueña de un colegio. Si la madre no es artista, el padre se mueve en "un grupo de intelectuales y artistas" de la talla del historiador Claudio Véliz, cuya capacidad intelectual y 
erudición "casi mágica" (29) le dará a SE a los dieciséis años su primer atisbo de lo que podría ser una carrera académica. Está bien conectado: contará con humor y una franqueza ejemplares cómo le fue posible cambiarse a la Universidad Católica sólo gracias a la intervención de su tío Gonzalo Figueroa, el mismo que le advierte del peligro que corre por su intervención en Qué Pasa, y a la vuelta de un viaje a Brasil, hasta los trámites de inmigración son agilizados por un ex ministro de hacienda, amigo de su abuela.

Pero los niños no se miden contra los estudios sociológicos o las estadísticas, sino contra sus pares. "En el colegio - ha contado SE en una autoentrevista para el diario La Tercera - yo era compañero de Agustín, hijo, y los profesores siempre se referían a mí como el Edwards pobre, el que llegaba en bicicleta o en micro, el que tenía los zapatos rotos, al que a veces la mamá lo iba a buscar en una citroneta destartalada": 3 es razonable su sensación de inferioridad respecto a los otros niños. A la hora de definir su adhesión política, entonces, nada más natural para él que escoger "un partido de verdad chileno y popular", el Partido Socialista, el de los chilenos de abajo, los chilenos como él. No quiere militar en el MAPU porque "se parecía a la kermesse de un colegio privado, donde todo el mundo se conocía desde siempre, donde muchos de los militantes eran rubios y de ojos azules" (50).

Pero el propio SE ha estudiado en un colegio privado, y si no es rubio, es al menos, en el léxico chileno, rucio. Su hermana tiene los ojos tan azules que a una brasileña que conocen en un bus "le recordaban el cielo azul de su ciudad natal" (229). Pobre para sus compañeros de colegio y a sus propios ojos, SE es inamoviblemente un "rico" para la masa de los chilenos por su apellido y su aspecto, hecho que resalta en el mismo comentario con el cual intenta distanciarse de esa casta.

Se trata de una confusión que remonta muy atrás, a la especie de pecado original que marcó el origen de los países de América con la independencia. En la versión oficial, llegaron europeos inescrupulosos a colonizar el continente y a expropiar y explotar a los pueblos originarios. Luego surgieron libertadores que expulsaron a los europeos y lograron la independencia. Lo que suele omitirse en ese relato es que los libertadores no eran los indígenas, los dueños originales de la tierra,

\footnotetext{
3 “Edwards entrevista a Edwards...", La Tercera, 2 de junio de 2016.
} 
sino los propios europeos o sus descendientes, los explotadores que conformaban el estrato superior de la sociedad y que ahora, convertidos por arte de magia en héroes de la independencia, estaban libres de seguir explotando a los lugareños — suponiendo que éstos no se hubieran eliminado antes, como en Argentina o Estados Unidos - sin la injerencia de la corona española o inglesa.

Fue el lavado de cara más osado de la historia; pero luego se realizaría una operación aún más audaz. En el transcurso de las décadas, el creciente poderío de Estados Unidos empezó a herir el orgullo de las élites latinoamericanas - a los campesinos indígenas que subsistían de la tierra les importaba menos-, y desarrollaron una nueva autoimagen que queda bien plasmada en un poema de Rubén Darío, "A Roosevelt", del cual SE cita un trozo en el contexto de una discusión sobre el ensayo de Eduardo Galeano de 1971, Las venas abiertas de América Latina. En la visión de Darío, se contrasta un Estados Unidos fuerte, rico y bárbaro, dueño del progreso material, con una América Latina que "tenía poetas / desde los viejos tiempos de Netzahualcóyotl", que "conoció la Atlántida" y que "vive de luz, de fuego, de perfume, de amor". Los versos que cita SE son: "Eres los Estados Unidos, / eres el futuro invasor / de la América ingenua que tiene sangre indígena, / que aún reza a Jesucristo y aún habla en español" (113). Es la usurpación última: el español, el idioma de los conquistadores que vino justamente a suplantar el de los poetas de "los viejos tiempos de Netzahualcóyotl", entre muchos otros, se reinventa como lengua originaria, y los colonizadores como víctimas del colonialismo.

Esa situación produce una dificultad para alguien como el SE joven, un integrante del estrato social superior - o, como él lo siente, un pobre varado en ese estrato- que quiere deponer el privilegio y unirse al pueblo, formar parte de la sociedad en su conjunto en vez de estar montado encima de ella. Ya tiene sonando en la cabeza un discurso de igualdad republicana originado en Europa, rematado por una retórica como la de Darío, con la que un pueblo unificado latinoamericano, espiritualmente refinado y con sangre indígena, se define por oposición a Estados Unidos. Más encima, si es socialista, tendrá sobrepuesto sobre ese discurso otro más, también europeo, de acuerdo al cual las divisiones que afligen a la sociedad son divisiones de clase. La forma de deponer el privilegio, entonces, sería salirse de la clase social superior para 
unirse al pueblo. Para un europeo, eso es difícil, pero no imposible: en principio, un aristócrata puede convertirse en un obrero sólo cambiando de acento, de ropa y de vida. Pero las divisiones en Latinoamérica, antes que de clase, son de raza. Haga lo que haga, un rucio de apellido Edwards jamás podrá ser un obrero. Está atrapado en su privilegio, víctima del pacto faustiano que le permitió a la casta europea mantener su dominio luego de la independencia: tendrá al pueblo en su poder, vivirá de su trabajo, lo obligará a acatar sus leyes, pero nunca será aceptado por él. Lo cual no implica que el discurso republicano sea vacío; refleja ideales auténticos, por consecuencia de los cuales se han ido desdibujando las desigualdades más ásperas, pero, como demuestra también el caso de los afroamericanos en Estados Unidos, el proceso puede ser largo, y hasta interminable.

SE en el fondo sabe todo eso, y de vez en cuando se sale del discurso republicano o socialista con un comentario que refleja la realidad, como el de los ojos azules de los militantes del MAPU. Pero ese lenguaje de clase social es el que todos usan, no sólo él, sino los que se encargan de informarle que no pertenece en ninguna parte: será un "pequeño burgués y revisionista" en la Universidad de Chile, un "traidor de clase" en la Católica.

Por mucho que SE se haya acostumbrado a la soledad, y a pesar de un espíritu contestatario visible ya en su juventud - basta con que su padre le prohíba entrar en una pieza de su casa que le sirve de laboratorio químico para que "decidiera que ese sería mi centro de operaciones" (237) por todo un verano- - en el fondo no es un solitario o un excéntrico. Le otorga un valor altísimo a la solidaridad, el capital social. Le resulta penoso constatar en una visita a Chile la separación radical entre ricos y pobres: "En una ciudad segregada no hay posibilidad de conocer al 'otro'... es difícil que se desarrolle la 'empatía"' (306). El pueblo unido imaginado por Darío y la UP no existe en Chile. O a lo mejor existe parcialmente, en los estratos populares, pero a éstos un Edwards nunca va a tener acceso.

Pero hay otro Chile, un lugar que ostenta los mismos veranos largos y despejados, los mismos cerros secos salpicados de arbustos y las mismas viñas y plantaciones de olivos, que comparte el mismo Pacífico salvaje. Es un Chile a través del espejo, donde el sol tras salir se dirige hacia el sur en vez del norte. Hay incontables personas con apellidos 
como Rodríguez, García o Martínez, pero su lugar en la sociedad no está del todo claro, tienen algo de foráneos, de advenedizos. Edwards, por el contrario - vuelvo a citar la autoentrevista de La Tercera-, es "un nombre del montón, un nombre popular, de obreros y funcionarios, de afroamericanos". Desde hace tres décadas y media, SE vive en California. $E P$ 